\title{
RACHEL DE QUEIROZ E A TRADUÇÃO NA DÉCADA DE 40 DO SÉCULO XX ${ }^{1}$
}

\author{
Priscilla Pellegrino de Oliveira \\ Maria Clara Castellões de Oliveira
}

\section{Introdução}

As décadas de 30 e 40 do século XX foram marcadas por acontecimentos que mudaram sobremaneira a configuração política mundial. Nesse momento, enquanto na Europa se desenrolava a Segunda Guerra Mundial (1939-1945), na América Latina surgiam vários governos ditatoriais. Entre 1937 e 1945, o Brasil, sob a liderança de Getúlio Vargas, viveu uma época de intensa repressão política, que ficou conhecida como o Estado Novo. Tal repressão se refletiu sobre diversos meios de expressão cultural, inclusive sobre a produção literária do período.

Rachel de Queiroz, nome importante na história literária do Brasil do século XX, iniciou sua carreira de escritora nos anos 30, tendo, na década seguinte, se dedicado quase que exclusivamente à tradução. A sua carreira como tradutora, no entanto, não se restringiu a esse momento. Como demonstrado por Érika Dias (2002) em monografia de conclusão do curso de Bacharelado em Letras: Ênfase em Tradução - Inglês da Universidade Federal de Juiz de Fora, a renomada escritora atuou como tradutora até a década de 1970, sendo que, nos anos 1960 e 1970, a sua prática tradutória esteve a serviço dos articuladores e sustentadores do golpe militar de 1964. Segundo Dias, nos anos em questão, Rachel de Queiroz não só escreveu diversas crônicas como também traduziu romances condizentes com o ideário anti-comunista daqueles que conspiraram e derrubaram o governo de João Goulart e o sucederam imediatamente. Surpreendentemente, as inclinações políticas demonstradas por Rachel de Queiroz nas

\footnotetext{
${ }^{1}$ Este trabalho, escrito em parceria, é uma versão adaptada para artigo da monografia de final do curso de Bacharelado em Letras: Ênfase em Tradução - Inglês da Universidade Federal de Juiz de Fora, defendida em julho de 2007 e realizada pela aluna Priscilla Pellegrino de Oliveira sob orientação da Profa. Maria Clara Castellões de Oliveira. Durante o período de consecução dessa monografia a aluna recebeu bolsa de Iniciação Científica da Pró-Reitoria de Pesquisa da UFJF. Versões dessa monografia foram apresentadas no IV Congresso Internacional de Tradução e Interpretação (CIATI), promovido pelo Centro Universitário Ibero-Americano - UNIBERO, em São Paulo, em maio de 2007, e no Simpósio "Tradução: Discursos, Linguagens, Cultura”, da XV Semana de Estudos Anglo-Germânicos da Universidade Federal do Rio de Janeiro, em outubro de 2007.
} 
décadas de 1960 e 1970 eram muito diferentes daquelas que possuía nas décadas de 1930 e 1940. Nessas duas décadas recém-mencionadas, Rachel de Queiroz teve participação ativa na fundação do partido comunista no Ceará, tendo se posicionado contrariamente à política estado-novista instaurada por Getúlio Vargas em 1937.

Um dos objetivos deste artigo é investigar a relação entre a atuação tradutória de Rachel de Queiroz nos anos 1940 e as relações de poder que se estabeleceram neste momento no Brasil. Nesse sentido, o presente trabalho suplementa as investigações conduzidas por Dias, inserindo-se, como as mesmas, no âmbito do projeto de pesquisa “Traduções Literárias: Jogos de Poder entre Culturas Assimétricas”, realizado no contexto do Bacharelado em Letras: Ênfase em Tradução - Inglês e do Programa de Pós-Graduação em Letras: Estudos Literários da UFJF.

No primeiro momento deste artigo, serão abordadas algumas ações empreendidas durante o Estado Novo que visaram à censura da produção intelectual e à sua canalização para fins pré-estabelecidos. Essas ações fizeram com que, particularmente nos anos 40 do século XX, muitos escritores optassem pela tradução como meio de sobrevivência, o que ocasionou um boom dessa atividade no Brasil. Para os propósitos estabelecidos, serão utilizados pensamentos de Sérgio Miceli, expostos em Intelectuais à brasileira (2001), e o conceito de patronagem, de André Lefevere (1992).

O momento seguinte será dedicado à atuação de Rachel de Queiroz como tradutora da Editora José Olympio nos anos 40 do século XX. Será destacado o lugar que a tradução ocupou no contexto da referida editora e da obra dessa escritora cearense. Os textos traduzidos por Rachel de Queiroz e publicados pela José Olympio, devido às línguas nas quais foram originalmente escritos e aos temas abordados, contribuíram para a alteração do funcionamento do sistema literário brasileiro, tendo se colocado como um reflexo das relações políticas e culturais que vinham dando novos rumos à configuração geopolítica mundial. Nesse momento, serão lembrados os pensamentos de Lawrence Venuti (2002) sobre os escândalos da tradução, e as teorias expostas por Itamar Even-Zohar $(1978,1979)$ acerca do polissistema literário.

Finalmente, a partir da análise das traduções do conto "Markheim”, do escritor inglês Robert Louis Stevenson, e do romance Mansfield Park, da escritora inglesa Jane Austen, serão tecidas considerações acerca da atividade tradutória de Rachel de Queiroz na década de 40 do século XX. Serão abordados não só os temas dos textos que traduziu, como também os procedimentos tradutórios utilizados. Para tanto, serão 
trazidos à tona os conceitos de estrangeirização e domesticação, construídos por Lawrence Venuti (1995, 2002), a partir de Friedrich Schleiermacher (1992).

\section{Censura, tradução e patronagem}

No período em que Getúlio Vargas instaurou a ditadura civil no país, entre as décadas de 1930 e 1940, o Estado procurou manter o controle sobre os mais diversos domínios de atividades, inclusive no campo da produção e difusão cultural. O governo passou a ser o principal investidor e promotor do mercado do livro no país e, como observou Sergio Miceli em Intelectuais à brasileira (2001):

[...] daí em diante, as instituições e os grupos cujas decisões repercutem na "substituição de importações" no plano cultural se diversificam de maneira considerável, envolvendo os mecenas [...], as diferentes faixas do público [...], e os produtores [...], além de sofrer o impacto causado pela difusão maciça de artigos culturais de origem norte-americana no âmbito do mercado internacional. (p. 80)

Devido ao interesse do governo em transmitir sua ideologia para a população, a educação passou a ser vista como forma de difusão desse ideário, além, é claro, de produzir mão-de-obra qualificada para o crescimento industrial. Em 1937, o governo criou o Instituto Nacional do Livro (INL), que tinha como uma de suas metas a produção de traduções escolhidas e subsidiadas, de interesse da cultura nacional, como pregava Vargas (Wyler, 2003). Ainda de acordo com Wyler, “as demais traduções passariam ao controle do Serviço de Divulgação da Chefatura de Polícia, criado no mesmo dia em que foi decretado o Estado Novo” (p. 109).

Em 1939, foi criado o Departamento de Imprensa e Propaganda (DIP), diretamente subordinado ao presidente, cujos objetivos eram censurar a imprensa, manipular a opinião pública e fazer propaganda do governo. O DIP era composto de cinco divisões: divulgação, radiodifusão, cinema e teatro, turismo e imprensa. Como descreveu Nelson Jahr Garcia em O Estado Novo: ideologia e propaganda política - a legitimação do Estado autoritário perante as classes subalternas (1982),

[...] suas atribuições eram de coordenação, superintendência, orientação, incentivo, promoção, direção, patrocínio, organização, auxílio e estímulo de: censura, propaganda nacional interna e externa, informações, turismo, manifestações artísticas em geral, manifestações cívicas, festas populares, concertos, conferências, exposições. (p. 100) 
Para difundir a ideologia do Estado Novo, o DIP promovia a edição de livros de conteúdo social e político, mesmo em romances e comédias. Muitas obras eram dedicadas a justificar o golpe de 1937, elogiar o regime e engrandecer a figura do líder. Tais livros eram publicados pelo próprio DIP ou editoras dispostas a oferecerem ajuda e amizade. Os que se manifestavam favoráveis ao regime recebiam subvenções e auxílios diversos. Na concepção de Garcia, “a cooptação de líderes e intelectuais foi uma das formas de resguardar o Estado Novo de contestação, a fim de manter a uniformidade ideológica” (p. 116).

Os estudos realizados por André Lefevere (1992) sobre a questão da patronagem se mostram relevantes para uma abordagem das relações estabelecidas pelo governo estado-novista no contexto da vida cultural brasileira, mais especificamente da literatura produzida e traduzida nesse momento. Segundo Lefevere, a patronagem, entendida como o poder exercido por pessoas, instituições, partidos políticos, classes sociais, editores e mídia sobre o sistema literário, está geralmente mais interessada na ideologia da literatura do que na sua poética. O patrocinador, agindo do lado de fora do sistema literário, não interfere diretamente no seu funcionamento e, sim, delega autoridade aos profissionais para fazê-lo em seu nome. Há, no sistema de patronagem, três elementos que podem interagir de várias maneiras: o ideológico, que determina a forma e o conteúdo do que será publicado; o econômico, que define a remuneração dos (re)escritores; e o status, que confere aos (re)escritores reconhecimento e prestígio. O sistema literário, segundo Lefevere, pode ser controlado por patronagens diferenciadas ou não-diferenciadas. A patronagem diferenciada centraliza o seu interesse no sucesso econômico e isso, necessariamente, não fornece status e não está a reboque de uma ideologia. Já a patronagem não-diferenciada envolve os três elementos — o ideológico, o econômico e o status. Nesse sentido, o patrocinador - que é sempre o mesmo tenta regular a relação entre o sistema literário e os outros sistemas de uma cultura. Ele controla o (re)escritor, o produto de seu esforço intelectual e a sua distribuição.

Foi, portanto, nesse contexto de patronagem não-diferenciada que a tradutora Rachel de Queiroz e vários de seus colegas escritores-tradutores atuaram durante o Estado Novo. Na verdade, é justamente em períodos de restrições políticas e de grande censura aos meios intelectuais que a patronagem se faz mais cabalmente nãodiferenciada. Assim sendo, desnecessário dizer que, nas décadas de 1960 e 1970, marcadas pela ditadura militar, Rachel de Queiroz também atuou em meio a uma patronagem não-diferenciada, como percebeu Dias (2001). 


\section{Rachel de Queiroz, tradutora da José Olympio nos anos 40 do século $\mathrm{XX}$}

De acordo com Heloísa Buarque de Hollanda (2005), após o sucesso de vendagens de seu primeiro livro, O Quinze, no Rio de Janeiro, Rachel de Queiroz "foi procurada por um então modesto editor, cuja firma se chamava Editora José Olympio. Daí nasceu uma associação entre ela, José e os irmãos Daniel e Athos, que durou 57 anos, quando a morte [de José Olympio] os separou” (p. 17). Durante esse tempo, foi essa editora que publicou a maior parte de suas obras e de suas traduções. De acordo com informações contidas em Cadernos de Literatura Brasileira (2002), foram 23 obras editadas e publicadas de autoria de Rachel de Queiroz, incluindo romances, peças de teatro, coletânea de crônicas e antologias. Desse total, 16 foram publicadas pela José Olympio em $1^{\text {a }}$. edição (cerca de $70 \%$ ), sem contar as reedições. Já com relação às traduções, dos 45 romances por ela traduzidos, 40 tinham o selo da José Olympio, ou seja, cerca 89\%. Apenas duas obras traduzidas foram publicadas pela Editora Delta na década de 60 e três pelas Edições Ouro na década de 70. Em 1991, a Editora José Olympio perdeu em leilão para a Editora Siciliano, de São Paulo, o direito de publicação da obra completa de Rachel de Queiroz.

A década de 40 foi o período em que Rachel de Queiroz mais traduziu, como pode ser observado no quadro abaixo.

\begin{tabular}{|l|c|c|c|c|c|c|}
\hline $\begin{array}{c}\text { Década } \\
\text { Produção }\end{array}$ & $\mathbf{3 0}$ & $\mathbf{4 0}$ & $\mathbf{5 0}$ & $\mathbf{6 0}$ & $\mathbf{7 0}$ & Total \\
\hline Romances & 4 & - & 1 & - & 1 & 6 \\
\hline Teatro & - & - & 3 & - & - & 3 \\
\hline (Livros de) Crônicas & - & 1 & 1 & 3 & 1 & 6 \\
\hline Obras conjuntas & - & 1 & - & 1 & 2 & 4 \\
\hline Livros traduzidos & - & 31 & 6 & 3 & 5 & 45 \\
\hline Total & 4 & 33 & 11 & 7 & 9 & 64 \\
\hline
\end{tabular}

Quadro 1: Produção literária de Rachel de Queiroz entre as décadas de 1930 e 1970 Fonte: Cadernos de Literatura Brasileira (2002)

O número de suas traduções suplantou o número de suas produções literárias. Seu último romance da década de 30 havia sido As três Marias, de 1939. A sua volta aos 
romances só viria a ocorrer em 1950, com O galo de ouro. É claro que a escritora também produziu textos de sua autoria para os jornais e revistas para os quais contribuía, no entanto, a sua atenção no período esteve voltada para a tradução. A profissão de tradutora lhe era rentável e satisfatória, como ela mesma afirmou:

Passei a ser tradutora efetiva, um livro atrás do outro e recebendo uma retirada mensal. Às vezes me ocorre fazer uma conta dos livros que traduzi nesse período. [...] Eu trabalhava regularmente oito a dez horas por dia; nisso ganhava a vida. [...] Eu chegava a traduzir tão rapidamente esse tipo de livros [best-sellers] que pagava uma datilógrafa para bater o que eu ditava. (Queiroz, 1999: 186-87)

Nessa década, de traduções intensas, que ocuparam a maior parte do tempo de Rachel de Queiroz e grande parte do tempo de outros escritores como Érico Veríssimo e Monteiro Lobato, a tradução exerceu umas de suas mais "escandalosas" funções (Venuti, 2002), qual seja, a de construir representações de culturas estrangeiras, estabelecendo centros e periferias. As editoras passaram a optar pela publicação de obras de ficção para o público feminino, de romances policiais e de histórias de aventura. No contexto das editoras brasileiras, "um terço dos romances - 52 títulos entre 156 publicados em 1942, sendo 62\% de traduções e 38\% de obras de autores nacionais — foi veiculado pelas diversas coleções endereçadas ao público feminino”, como apontou Miceli (2001: 154). Ainda segundo Miceli, “os outros romances publicados nesse mesmo ano [1942] eram, em sua maioria, obras de clássicos europeus, antigos e modernos, de romancistas norte-americanos em vias de consagração ou, então, best-sellers" (p. 154).

A partir do quadro 2, apresentado a seguir, é possível obter uma compreensão do papel que Rachel de Queiroz e a editora José Olympio desempenharam, através de traduções que trouxeram a público, na reconfiguração do sistema literário brasileiro.

\begin{tabular}{|l|c|c|}
\hline \multicolumn{1}{|c|}{ Autor } & Título traduzido & $\begin{array}{c}\text { Língua de } \\
\text { partida }\end{array}$ \\
\hline 1. Jane Austen & Mansfield Park & Inglês \\
\hline 2. Honoré de Balzac & A mulher de trinta anos & Francês \\
\hline 3. Vicki Baum & Helena Wilfuer & Inglês \\
\hline 4. Henry Bellamann & A intrusa & Inglês \\
\hline 5. Phyllis Bottone & Tempestade d'alma & Inglês \\
\hline 6. Emily Brontë & Os Robinsons da montos uivantes & Inglês \\
\hline 7. André Bruyere & A promessa & Francês \\
\hline 8. Pearl Buck & A exilada: retrato de uma mãe americana & Inglês \\
\hline 9. Pearl Buck & \multicolumn{2}{|c|}{ Inglês } \\
\hline
\end{tabular}




\begin{tabular}{|c|c|c|}
\hline 10. Samuel Butler & Destino da carne & Inglês \\
\hline 11. Archibald J. Cronin & A família Brodie & Inglês \\
\hline 12. Archibald J. Cronin & Anos de ternura & Inglês \\
\hline 13. Archibald J. Cronin & Aventuras da maleta negra & Inglês \\
\hline $\begin{array}{l}\text { 14. Mario Donal, } \\
\text { pseudônimo de Marie } \\
\text { Chambon }\end{array}$ & O quarto misterioso e congresso de bonecas & Inglês \\
\hline 15. Fiódor Dostoievski & Humilhados e ofendidos & $\begin{array}{c}\text { Francês } \\
\text { Trad. indireta }\end{array}$ \\
\hline 16. Fiódor Dostoievski & Recordações da casa dos mortos & $\begin{array}{c}\text { Francês } \\
\text { Trad. indireta }\end{array}$ \\
\hline 17. Daphne Du Maurier & O roteiro das gaivotas & Inglês \\
\hline 18. Alexandre Dumas & Memórias de Alexandre Dumas, pai & Francês \\
\hline 19. John Galsworth & A crônica dos Forsyte (3 volumes) & Inglês \\
\hline 20. Elisabeth Gaskell & Cranford & Inglês \\
\hline 21. James Hilton & Fúria no céu & Inglês \\
\hline 22. Marie de La Contrie & Aventuras de Carlota & Francês \\
\hline 23. Yves Loisel & A casa dos cravos brancos & Francês \\
\hline 24. Olive Prouty & Stella Dallas & Inglês \\
\hline 25. Erich Maria Remarque & Náufragos & Inglês \\
\hline 26. Forrest Rosaire & Os dois amores de Grey Manning & Inglês \\
\hline 27. Irwin Stone & Mulher imortal & Inglês \\
\hline 28. Teresa de Jesus, Santa & Vida de Santa Teresa de Jesus & Espanhol \\
\hline 29. Leon Tolstoi & Memórias & Francês \\
\hline 30. Germaine Verdat & A conquista da torre misteriosa & Francês \\
\hline 31. Judith Wharton & Eu soube amar & Inglês \\
\hline
\end{tabular}

Quadro 2: Listagem das obras traduzidas por Rachel de Queiroz na década de 40 do século XX

Os dados fornecidos no quadro 2 permitem que se observe a contribuição de Rachel de Queiroz para a sedimentação do inglês como o principal idioma de tradução no contexto brasileiro. A língua inglesa, nesse cenário, sobrepujou a língua francesa devido a mudanças histórico-sociais discutidas anteriormente. Entre os romances traduzidos no período em questão, apenas um foi escrito originalmente em espanhol (3\%), enquanto nove - $29 \%$ - foram traduzidos do francês e 21 - cerca de $68 \%$ do inglês. Sobre a demanda por textos de literaturas de língua inglesa, Rachel de Queiroz comentou: “adestrei-me então no inglês, no qual até então era fraca, desde que Vera Pereira, mulher de José Olympio, assumiu a escolha de autores a traduzir — e ela gostava de literatura inglesa” (Queiroz, 1999: 187).

A esposa de José Olympio era uma mulher enérgica, culta e independente, formada em Filosofia e possuidora de ampla experiência no exterior. Além disso, era 
uma leitora competente de textos em francês e em inglês. Na editora, dedicava-se "à seção de livros estrangeiros, aos best-sellers, às traduções. Precisamente por causa do seu domínio de línguas e sua ampla cultura universal” (Villaça, 2001: 139). Através da pena de Rachel de Queiroz, Vera Pereira contribuiu para a difusão não apenas das literaturas de língua inglesa no Brasil como também da literatura feminina. Observa-se no quadro acima que, apesar de a literatura escrita por homens ainda ser maioria, foi traduzido um número expressivo de romances escritos por mulheres. Das 31 obras traduzidas, 13 - aproximadamente $42 \%$ - foram de autoria feminina. Das 18 restantes, escritas por homens, quatro têm claramente temática feminina, ou seja, cerca de $13 \%$ dos romances traduzidos por Rachel de Queiroz.

A tradução por parte de Rachel de Queiroz para a Editora José Olympio de obras de autoria e temática femininas e de outras tantas oriundas de literaturas de língua inglesa na década de 1940 revelou-se uma das conseqüências de mudanças que estavam ocorrendo na sociedade mundial de então e, mais especificamente, na brasileira. Em nosso contexto, Getúlio Vargas, que governava o país desde 1930, tomou uma série de medidas que imprimiram maior visibilidade ao papel desempenhado pela mulher em sociedade. A partir da década de 1930, por exemplo, a mulher adquiriu o direito de votar e de se candidatar a cargos públicos. Por outro lado, o papel de destaque ocupado pela Grã-Bretanha ao longo da Segunda Guerra Mundial e pelos Estados Unidos da América nesse mesmo momento e nos anos imediatamente posteriores a esse catastrófico evento deu novos rumos à ditadura instaurada por Vargas, que se rendeu ao poderio bélico, político e econômico de tais nações. Esses fatos corroboram a tese de Itamar Even-Zohar, exposta em "Polysystem theory" (1979) e "The position of translated literature within the literary polysystem" (1978), sobre o quanto o polissistema literário, e, conseqüentemente, o sistema de literatura traduzida se deixam influenciar por alterações que acontecem em outras esferas da cultura.

\section{As traduções de “Markheim” e Mansfield Park por Rachel de Queiroz}

Para fins do presente trabalho, serão abordadas as traduções feitas por Rachel de Queiroz de um conto, “Markheim”, de Robert Louis Stevenson, e de um romance, Mansfield Park, de Jane Austen. As pesquisas realizadas no âmbito do projeto “Traduções Literárias: Jogos de Poder entre Culturas Assimétricas” apontaram para o fato de que, além de ter se dedicado à tradução de romances, Rachel de Queiroz traduziu contos, publicados esparsamente. Até o presente momento, sabe-se da 
existência de dois deles, realizados na década de 40 do século XX: o que será objeto de nossa atenção e “O diabo e Daniel Webster”, de Stephen Vincent Benet.

As análises aqui empreendidas valem-se de dois conceitos erigidos por Lawrence Venuti (1995, 2002) a partir do ensaio “Über die verschiedenen Methoden des Übersetzens” (literalmente “Sobre os diferentes métodos de tradução”), de Friedrich Schleiermacher, publicado em 1813. São eles os conceitos de estrangeirização e de domesticação. Segundo o filósofo alemão, o tradutor tem duas escolhas a fazer ao se dedicar à sua tarefa: conduzir o leitor até o escritor ou trazer o escritor até o leitor. Disse ele:

O tradutor ou deixa o escritor sozinho tanto quando possível e conduz o leitor em direção ao escritor, ou deixa o leitor sozinho o tanto quanto possível e conduz o escritor em direção ao leitor. [...] no primeiro caso, o tradutor se esforça, através de seu trabalho, para compensar a falta de entendimento da língua original por parte do leitor. Ele procura comunicar a seus leitores a mesma imagem, a mesma impressão que ele próprio teve - a partir de seu conhecimento da língua do original — da obra assim como ela se encontra, e, portanto, conduzir os leitores a seu ponto de vista, que é, na verdade, estrangeiro a eles. Se, contudo, a tradução procura deixar o seu autor romano, por exemplo, falar como ele teria falado e escrito como um alemão para alemães, ela não move o autor para onde o tradutor está porque o autor não fala alemão para ele, mas sim latim; ao contrário, ela conduz o autor imediatamente para o mundo dos leitores alemães e o transforma em um deles — e este é precisamente o outro caso. (1992: 42, nossa tradução)

A primeira alternativa caracterizaria, para Venuti, o processo de estrangeirização e a segunda, o processo de domesticação. Os dois teóricos da tradução, cada um deles em seu tempo e lugar, defenderam, por motivos não necessariamente coincidentes - que não cabem ser discutidos aqui — o processo de estrangeirização. Nas palavras de Venuti, "sob o regime da tradução fluente, o/a tradutor(a) trabalha para tornar a sua obra 'invisível', produzindo o efeito ilusório da transparência que simultaneamente mascara o seu status como uma ilusão: o texto traduzido parece ‘natural', i.e., não traduzido” (1995: 5, nossa tradução). Por outro lado,

[...] na tradução estrangeirizante, a violência etnocêntrica que todo ato de tradução inflige em um texto estrangeiro se iguala a uma ruptura violenta dos valores domésticos que desafia formas culturais de dominação, quer nacionalistas ou elitistas. A estrangeirização solapa o próprio conceito de nação ao invocar as diversas questões que qualquer conceito como esse tende a omitir. (1995: 147, nossa tradução)

Como reconheceu Schleiermacher (1992), uma exigência essencial da tradução estrangeirizante “é uma atitude diante da língua que é não apenas trivial, mas que 
também nos deixa saber que ela não nasceu completa e livremente, mas que, ao contrário, foi moldada em direção a uma semelhança estrangeira. Deve-se admitir que fazer isso com habilidade e moderação, sem o prejuízo para a língua do tradutor e para si próprio, é talvez a maior dificuldade que um tradutor tem que suplantar” (p. 46, nossa tradução).

\subsection{A tradução de "Markheim"}

Stevenson, romancista, poeta e ensaísta escocês, mais conhecido por seus romances de aventura e suspense, escreveu "Markheim” em 1885. Sua obra mais famosa, Dr. Jekyll and Mr. Hyde, é "uma alegoria entre as forças do bem e do mal que se debatem na personalidade humana”, segundo Ifor Evans em História da literatura inglesa (1976: 307). Essa temática será encontrada no conto em questão, traduzido por Rachel de Queiroz nos anos 40 do século passado, recentemente publicada no livro Contos Ingleses (2004), organizado por Rubem Braga

O conto, que traz elementos sobrenaturais em estilo vitoriano, caracterizado por uma moralidade profundamente conservadora, narra um dia ocorrido na vida do protagonista — o judeu Markheim. O personagem está em Londres e entra em uma loja de antiguidades com intenção de roubar, fazendo-se passar por um cliente. Em seguida, mata o negociante e decide entrar em sua casa, que fica no andar superior. Apesar de ter se certificado de estar só, Markheim tem a constante sensação de estar sendo observado e, por esse motivo, sente-se apavorado. De repente, como uma resposta a seus temores, surge alguém: uma figura sombria e misteriosa. Tal figura parece conhecer Markheim intimamente e se oferece para ajudá-lo. Começa, então, uma luta do personagem principal — dividido entre o bem e o mal — com sua consciência.

Durante o diálogo estabelecido entre Markheim e esse outro que se lhe apresenta, o primeiro deixa claro que esse não foi o seu único crime, mas será o último, pois só precisa do dinheiro para pagar dívidas de jogo. O seu interlocutor prevê os próximos acontecimentos da vida de Markheim, dizendo que o mesmo continuará vivendo na criminalidade. No entanto, ao final da trama, o protagonista decide se entregar quando vê surgir na sala a criada do homem que assassinara. Nesse momento, a figura sinistra com quem dialogava desaparece.

A moralidade embutida no conto se apresenta através da consciência culpada do protagonista e na sua decisão de remissão diante da tentação de continuar pecando. Dessa forma, Markheim é representado no texto como um ser humano comum, dividido 
entre as forças dúbias da natureza humana. De fato, reconhecendo-se falho e pecador, ele se afasta do estereótipo literário do judeu:

Se estou condenado a cometer crimes, pelo menos ainda me resta uma porta escapatória: posso deixar de agir. Se minha vida é uma coisa má, posso pelo menos mantê-la imóvel. Embora, segundo você o disse com a verdade na boca, eu esteja à mercê da menor tentação, ainda posso, graças a um gesto decisivo, colocar-me fora do alcance de todas elas. Meu amor ao bem está condenado à esterilidade: pode ser, e vá lá que seja! Mas resta-me o ódio ao mal. E para mortificação e desapontamento seu, verá que desse ódio hei de haurir energia e coragem. (Stevenson, 2004: 125)

Em uma época marcada pelo preconceito contra o povo judaico, Rachel de Queiroz traduziu um texto filo-semita com o aval de José Olympio, que discordava da perseguição ao povo judeu nos anos 1930 e 1940 e se mostrava contrário à publicação de obras que denegrissem a imagem desse povo. Prova disso é o fato de que o empresário se recusou a publicar obras como Brasil - colônia de banqueiros e Judaísmo, maçonaria e comunismo, apesar de ter sido o editor favorito dos integralistas. Além disso, segundo Laurence Hallewell, em O livro no Brasil: sua história (1985), José Olympio "publicou obras em defesa do povo judeu, tais como Les juifs, de Paul Claudel, Jacques Maritain, Denis de Rougement, André Spire, Georges Cattaui e outros proeminentes intelectuais cristãos liberais. Esse livro saiu em 1938, com o título de Os Judeus, em tradução de Jorge de Lima, que a ela acrescentou um poema de sua autoria, 'Invocação a Israel'”' (p. 365).

Por outro lado, a ligação de Rachel de Queiroz com o contexto judaico era motivada por várias razões. Além de o seu círculo de amizade ser composto por diversas pessoas de origem judaica, a sua família, mais especificamente o ramo dos Alencar, era descendente de cristãos novos que saíram da Europa na época da Inquisição e foram mandados para Pernambuco, onde deram continuidade às suas práticas religiosas. Em entrevista publicada em Cadernos de Literatura Brasileira (2002), a escritora mencionou ter ficado feliz ao descobrir suas raízes judaicas, tendo acrescentado que essa ascendência se manifestava mais em sua forma de ser do que em sua produção literária.

Como tradutora de "Markheim”, Rachel de Queiroz comportou-se de forma inovadora não apenas por ter se dedicado a traduzir um conto filo-semita em um momento delicado para o povo judaico em exílio na Europa, como também por ter contribuído para a sedimentação da língua inglesa como a principal língua de tradução 
no Brasil. No processo de tradução do conto de Stevenson, Rachel de Queiroz, a exemplo do que fizeram outros tradutores do período, como Érico Veríssimo, ao traduzir "Bliss", de Katherine Mansfield (1940), deixou presentes no texto em português palavras que remetiam à língua do original, como pode ser observado nos trechos abaixo:

\begin{tabular}{|c|c|}
\hline ORIGINAL & TRADUÇÃO DE RACHEL DE QUEIROZ \\
\hline $\begin{array}{l}\text { 1. [...] the faint rushing of the cabs in a near } \\
\text { thoroughfare, filled up the interval of silence } \\
\text { (p. 1, nossos grifos). } \\
\text { 2. [...] the day blind with fog; and the light } \\
\text { that filtered down to the ground story was } \\
\text { exceedingly faint (p. } 4 \text {, nossos grifos). }\end{array}$ & $\begin{array}{l}\text { 1. [...] o fraco som dos cabs a rolar na rua, lá } \\
\text { longe, encheram aquele intervalo de silêncio } \\
\text { (p. 112). } \\
\text { 2.[...] o dia estava enevoado de fog; e a luz } \\
\text { que escorria até o chão era muito tênue } \\
\text { (p.116). }\end{array}$ \\
\hline
\end{tabular}

A presença da língua do original no texto traduzido caracteriza, nos termos de Venuti (1995), um procedimento de tradução estrangeirizante. No entanto, ao mesmo tempo em que demonstrou preocupação de marcar a origem do texto, conferindo-lhe uma cor local, ela se preocupou em dotar a tradução de um caráter fluente, transparente, típico das traduções domesticantes. Nesse sentido, Rachel de Queiroz adaptou o texto para torná-lo mais idiomático, como observa-se nos exemplos seguintes:

\begin{tabular}{|l|l|}
\hline \multicolumn{1}{|c|}{ ORIGINAL } & \multicolumn{1}{|c|}{ TRADUÇÃO DE RACHEL DE QUEIROZ } \\
\hline $\begin{array}{l}\text { 1. [...] and the painted Jacobean tombs, and } \\
\text { the dim lettering of the Ten Commandments } \\
\text { in the chancel. (p. 7, nossos grifos) }\end{array}$ & $\begin{array}{l}\text { 1. [...] os túmulos pintados dos tempos do rei } \\
\text { James I, e as letras escuras em que estavam } \\
\text { gravados os Dez Mandamentos, no coro. (p. } \\
120, \text { nossos grifos) }\end{array}$ \\
$\begin{array}{l}\text { 2. I am the essence of discretion [...]. (p. 1, } \\
\text { nossos grifos) }\end{array}$ & $\begin{array}{l}\text { 2. Sou a discrição em carne e osso [...]. (p. } \\
112, \text { nossos grifos) }\end{array}$ \\
\hline
\end{tabular}

No primeiro exemplo, em vez de traduzir Jacobean tombs por túmulos jacobitas, Rachel de Queiroz utilizou a expressão túmulos (pintados) dos tempos do rei James I. Dessa forma, explica-se a origem histórica do termo pertencente à cultura do texto original. Já no segundo exemplo, a tradutora optou por utilizar a expressão idiomática 
brasileira em carne e osso como substituta de the essence of. Tal trecho poderia ter sido traduzido literalmente por a essência da. Entretanto, o termo escolhido por Rachel de Queiroz torna a passagem mais fluente para o leitor brasileiro.

Há um terceiro ponto interessante a se notar na tradução de "Markheim” por Rachel de Queiroz. A autora traduziu, ao longo de todo o texto, a palavra mind por espírito. Os trechos a seguir contrastam original e tradução:

\begin{tabular}{|c|c|}
\hline ORIGINAL & TRADUÇÃO DE RACHEL DE QUEIROZ \\
\hline $\begin{array}{l}\text { 1. And still, as he continued to fill his } \\
\text { pockets, his mind accused him with a } \\
\text { sickening iteration, of the thousand faults of } \\
\text { his design. (p. 3, nossos grifos) }\end{array}$ & $\begin{array}{l}\text { 1. E embora continuasse ele a encher os } \\
\text { bolsos, o espírito o acusava, com irritante } \\
\text { repetição, de milhares de lacunas no seu } \\
\text { plano. (p. 115, nossos grifos) }\end{array}$ \\
\hline $\begin{array}{l}\text { 2. [...] incessant toiling of the mind to change } \\
\text { what was unchangeable [...]. (p.3, nossos } \\
\text { grifos) }\end{array}$ & $\begin{array}{l}\text { 2. [...] uma incessante labuta do espírito } \\
\text { querendo mudar o que era imutável [...]. (p. } \\
\text { 115, nossos grifos) }\end{array}$ \\
\hline $\begin{array}{l}\text { 3. [...] with no conscious repugnance of the } \\
\text { mind, yet with a tremor of the belly, he drew } \\
\text { near the body of the victim. (p. } 5 \text {, nossos } \\
\text { grifos) }\end{array}$ & $\begin{array}{l}\text { 3. [...] sem nenhuma repugnância consciente } \\
\text { no espírito, mas com um tremor nas } \\
\text { entranhas, aproximou-se do corpo da vítima } \\
{[\ldots . . \text {. (p. 117, nossos grifos) }}\end{array}$ \\
\hline $\begin{array}{l}\text { 4. And are my vices only to direct my life, } \\
\text { and my virtues without effect, like some } \\
\text { passive lumber of the mind? (p. 9, nossos } \\
\text { grifos) }\end{array}$ & $\begin{array}{l}\text { 4. E então, só meus vícios hão de dirigir } \\
\text { minha vida, e minhas virtudes permanecerão } \\
\text { inúteis, como um traste inútil do espírito? (p. } \\
124 \text {, nossos grifos) }\end{array}$ \\
\hline
\end{tabular}

O conto de Stevenson traduzido por Rachel de Queiroz estabelece um diálogo com a lenda medieval que deu origem ao texto dramático Dr. Faustus, do autor inglês Christopher Marlowe, recontada por diversos outros autores ao longo dos tempos. Essa lenda é protagonizada por Fausto, que vendeu sua alma ao diabo, Mefistófeles. Se levarmos em consideração que o sentido da palavra espírito está bem mais próximo de alma do que do sentido da palavra mente, então podemos dizer que Rachel de Queiroz fez uma escolha proposital ao tornar mais explícito em sua tradução a interlocução existente entre a obra de Stevenson e a lenda medieval. 


\subsection{A tradução de Mansfield Park}

A análise da tradução feita por Rachel de Queiroz do romance Mansfield Park, de Jane Austen, justifica-se em função do fato de ser esta uma obra de autoria feminina, que discute o lugar da mulher na sociedade em um ambiente rural. Assim como nas obras de autoria de Rachel de Queiroz, tal ambiente é determinante para o comportamento das personagens. Além disso, nos textos da escritora cearense, assim como nos romances de Austen, as personagens femininas têm papel de destaque e a história gira em torno de suas aspirações. No caso de Mansfield Park, a protagonista, Fanny Price, simboliza a mulher reprimida que ocupa uma posição secundária na sociedade por ter nascido em uma família sem recursos financeiros e ter sido adotada pela rica família da tia. Uma visão de sua atitude ao longo da trama pode ser obtida através do seguinte fragmento de texto:

Fanny não tomou parte nos divertimentos da estação; mas encontrava prazer em ser reconhecidamente util a sua tia, quando o resto da familia se ausentava [...]. Quanto aos divertimentos das primas, gostava de ouvir falar sobre eles [...] mas fazia de sua propria situação um tão baixo conceito que nunca imaginava poder tomar parte neles e por isso ouvia como se fossem cousas muito distantes dela. (1958: 32, nossos grifos) ${ }^{2}$

Como antagonista da personagem principal, surge Mary Crawford, cunhada do segundo pastor de Mansfield Park, educada por parentes na cidade e recém-chegada à propriedade. Seu discurso mostra que não é uma moça de idéias provincianas como alguns membros da família Bertram esperavam, o que pode ser observado nos trechos a seguir:

- Aí está, arrisco minha última ficha, como uma mulher de coragem. Comigo não admito prudencia. Não nascí para ficar parada e não fazer nada. Se eu perder a partida, não será por não ter lutado para ganhá-la. (1958: 205, nossos grifos)

[...]

— Ah, Fanny, ouvir a mulher amada não achar para aquilo outro nome senão "loucura”! Descrever aquilo tão voluntariamente, tão friamente, tão livremente! Sem relutância, sem horror, sem timidez feminina, e, ousaria dizê-lo? sem modéstia nem repugnância! Eis o que o mundo faz de uma moça! Onde encontrariamos entretanto, Fanny, uma mulher tão ricamente dotada pela natureza? Corrompida, corrompida! (1958: 384, nossos grifos)

\footnotetext{
${ }^{2}$ Essa citação em português, assim como as que seguirão, foi feita a partir da versão de Mansfield Park traduzida por Rachel de Queiroz. Deve-se lembrar que, nesse momento, as regras ortográficas e de acentuação de palavras eram diferentes das que estão atualmente em vigor.
} 
Assim como na tradução do conto “Markheim”, Rachel de Queiroz ao trazer para a língua portuguesa do Brasil o romance de Austen, se posicionou de maneira estrangeirizante em diversos aspectos, tendo sido encontrados vários exemplos de manutenção da língua inglesa no texto traduzido. Em primeiro lugar, todos os nomes próprios, tanto de pessoas quanto de lugares, foram mantidos, assim como os títulos referentes às personagens, como, por exemplo, Miss Crawford, Lady Bertram, Mrs. Grant e Sir Thomas. Em outros poucos momentos ocorreu a conservação de trechos do texto estrangeiro sem sequer uma nota de rodapé ou uma tentativa de tradução, como na passagem seguinte, em que há uma citação de uma obra literária e é apresentada uma paródia desta feita por uma das personagens:

- Sir Thomas vai fazer grandes cousas quando voltar para casa, disse Mary depois de um intervalo. Você se lembra do "Address to Tobacco", de Hawkins Brawne, na imitação de Pope?

"Blest leaf! whose aromatic gales dispense

To Templars modesty, to Parsons sense".

Eu faço a seguinte parodia:

"Blest Knight! whose dictatorial looks dispense

To children affluence, to Rushworth sense".

(1958: 138, nossos grifos)

Os vocábulos hall e gentleman também não foram traduzidos pela autora. De qualquer forma, a sua manutenção no texto em itálico traz uma cor local a ele, que, ao mesmo tempo em que identifica a sua origem, demonstra a importância que a língua inglesa já possuía naquele momento no contexto brasileiro:

\begin{tabular}{|l|l|}
\hline \multicolumn{1}{|c|}{ TEXTO ORIGINAL } & \multicolumn{1}{|c|}{$\begin{array}{c}\text { TRADUÇÃO DE RACHEL DE } \\
\text { QUEIROZ }\end{array}$} \\
\hline $\begin{array}{l}\text { 1. A glimpse, as she passed through the } \\
\text { hall, of the two ladies walking up from the } \\
\text { Parsonage [...]. (p. 171, nossos grifos) }\end{array}$ & $\begin{array}{l}\text { 1. Ao atravessar o hall, avistou as duas } \\
\text { senhoras vindo do Presbiterio [sic] [...]. (p. } \\
\text { 143) }\end{array}$ \\
$\begin{array}{l}\text { 2. He stopped; and, ungentlemanlike as he } \\
\text { looked [...]. (p. 408, nossos grifos) }\end{array}$ & $\begin{array}{l}\text { 2. Mr. Price parou, e por menos que ele } \\
\text { semelhasse a um gentleman, [...]. (p. 338) }\end{array}$ \\
\hline
\end{tabular}

Entretanto, na maior parte do texto, Rachel de Queiroz se comportou de forma domesticante, pois mostrou preocupação em tornar o texto mais fluente para o leitor brasileiro. Como ilustração, destaca-se um trecho que menciona uma peça do 
dramaturgo alemão do século XVIII August Von Kotzebue, intitulada “Lover’s vows”: “A peça escolhida tinha sido 'Lover’s Vows’ (Juras de amor), e Mr. Yates faria o papel de Conde Cassel” (p. 105, nossos grifos). Ao traduzir, entre parênteses, o nome da peça, a autora trouxe para o leitor, além do título original, a tradução literal do mesmo, que permite que se obtenha uma visão da temática escolhida pelas personagens, já que o clima era de romance entre algumas delas. A partir desse momento, sempre que a peça foi mencionada na história, a tradução passou a trazer somente o título fornecido entre parênteses, “Juras de amor”. Mais adiante, em uma descrição da discussão dos jovens sobre as peças a se escolher, a autora as colocou todas traduzidas para o português, sem menção aos títulos originais:

As melhores peças foram todas estudadas inutilmente. Nem "Hamlet", nem "Macbeth" nem "Otelo", nem "Douglas", nem "O Jogador", apresentavam qualquer cousa que pudesse satisfazer até mesmo os trágicos; e "Os Rivais”, "A Escola de Escândalo", "Roda da Fortuna”, "Herdeiros por Lei” e muitos et coeteras [...]. (1958: 112)

Outra maneira pela qual Rachel de Queiroz imprimiu fluência ao texto traduzido foi através de ajustes sintáticos ao texto original, que caracterizam procedimentos domesticantes de tradução. Os trechos abaixo ilustram o que foi dito:

\begin{tabular}{|l|l|}
\hline \multicolumn{1}{|c|}{ TEXTO ORIGINAL } & \multicolumn{1}{|c|}{ TRADUÇÃO DE RACHEL DE } \\
QUEIROZ
\end{tabular}

No primeiro exemplo, o trecho original apresentou o pronome pessoal da primeira pessoa do singular - $I$, pois, ao contrário do que acontece em português, em inglês o mesmo se faz necessário devido à falta de desinências verbais que indiquem 
pessoa. Percebe-se que Rachel de Queiroz utilizou somente o verbo garanto, sem mencionar textualmente a pessoa referida. Em inglês, fez-se o uso do verbo modal will e do verbo auxiliar do nas formas afirmativa e negativa para se referirem a algo que foi dito anteriormente, sem necessidade de repetir o verbo principal, seja ele qual for. Em português, o verbo principal foi repetido - no caso, guardar, pois não se utiliza nessa língua o verbo auxiliar para responder a uma pergunta ou evitar uma repetição. No segundo exemplo, além de a tradutora ter feito uma inversão na ordem das orações, ela também omitiu um trecho do original na tradução — in the least, tornando a passagem bem mais sucinta. No terceiro exemplo, ocorreu o uso do verbo auxiliar did, logo antes do verbo principal mean, em uma frase afirmativa, o que imprimiu ênfase na fala da personagem. O mesmo não aconteceu em português. Poder-se-ia utilizar o advérbio sim para tal ênfase, obtendo-se um efeito parecido. Porém, a autora preferiu deixar o trecho mais simples, sem a adição de algo parecido. Ainda no mesmo exemplo, há um trecho em inglês que foi bem simplificado pela tradutora: she could not but be thankful seria algo como ela não poderia fazer coisa alguma a não ser agradecer. A solução encontrada por Rachel de Queiroz foi bem mais simples: ficou agradecida.

Exemplos como os comentados são os mais freqüentes na tradução de Rachel de Queiroz, o que demonstra que a mesma, ao optar por um texto mais idiomático do que literal, forneceu ao público-leitor uma visão do estilo da autora britânica que não condiz com aquele que é percebido quando o texto é lido em seu original em língua inglesa.

\section{Considerações finais}

As análises da lista de textos traduzidos por Rachel de Queiroz ao longo de sua vida apontaram para o fato de ter sido na década de 40 do século XX que ela mais traduziu. Ademais, essas análises e aquelas das traduções do conto "Markheim”, de Robert Louis Stevenson, e do romance Mansfield Park, de Jane Austen, fornecem evidência para o fato de que a escritora cearense comportou-se de forma culturalmente estrangeirizante, pois não apenas trouxe para o contexto brasileiro textos em sua maioria provenientes da língua inglesa, cuja origem deixou clara no corpo das traduções, como também dedicou grande parte de seu esforço à tradução de textos que seriam considerados marginais no período, por serem de autoria feminina e por abordarem temáticas femininas e politicamente delicadas. Em termos lingüísticos, tanto na tradução de “Markheim” quanto na de Mansfield Park, Rachel de Queiroz comportou-se de 
forma domesticante, procurando construir um texto que parecesse ao leitor brasileiro ter sido escrito originalmente em língua portuguesa.

Por refletir as mudanças ocorridas nos contextos político e econômico mundial e brasileiro, a produção tradutória de Rachel de Queiroz na década de 40 do século XX serve de evidência para as reivindicações de Even-Zohar $(1978,1979)$ sobre as intensas relações de troca entre os vários polissistemas que constituem a cultura. Ademais, as relações de patronagem existentes na década de 40 do século XX revelaram que a autora atuou de acordo com o prescrito pelo poder vigente - apesar de ser radicalmente contra as ações controladoras de Getúlio Vargas, fato que viria a determinar a sua postura antijanguista, traduzida em apoio explícito às forças que conspiraram para derrubar o seu governo da década de1960 e instaurar e manter os governos militares que se seguiram. Na década de 40 do século passado, Rachel de Queiroz trabalhou para uma empresa que, até mesmo por questões de sobrevivência, necessitava manter estreitas relações com o poder.

Para finalizar, torna-se relevante enfatizar que estudos sobre a prática tradutória de escritores como Rachel de Queiroz em um momento como a década de 40 do século XX descortinam relações de poder estabelecidas pela nação brasileira cujos reflexos extrapolam o espaço e o tempo em que as mesmas se deram. Por esse motivo, tais estudos conferem um lugar de destaque à tradução tal como realizada por Rachel de Queiroz, além de contribuírem para a construção de uma historiografia da tradução no Brasil.

\section{Referências}

AUSTEN, Jane (1994) Mansfield Park. London: Penguin Books.

(1958) Mansfield Park. Trad. Rachel de Queiroz. 2a . ed. Rio de Janeiro: José Olympio.

Cadernos de literatura brasileira: Rachel de Queiroz (2002) Número 4 - setembro de 1997, $1^{\text {a }}$. reimpressão. São Paulo: IMS.

DIAS, Érika Paula Faria (2002) As traduções de Rachel de Queiroz nas décadas de 60 e 70 do século XX. Juiz de Fora: Departamento de Letras Estrangeiras Modernas da UFJF (Monografia de conclusão do Bacharelado em Letras: Ênfase em Tradução - Inglês).

EVANS, Ifor (1976) História da literatura inglesa. Trad. A. Nogueira Santos. São Paulo: Martins Fontes. 
EVEN-ZOHAR, Itamar (1978) "The position of translated literature within the literary polysystem”. J. S. Holmes et al. (orgs.) Literature and translation: new perspectives in literary studies, 117-127. Leuven: Acco.

EVEN-ZOHAR, Itamar (1979) Polysystem theory. Poetics Today 1 (1, 2), 287-310.

GARCIA, Nelson Jahr (1982) O Estado Novo: ideologia e propaganda política: a legitimação do estado autoritário perante as classes subalternas. São Paulo: Loyola.

HALLEWELL, Laurence (1985) O livro no Brasil: sua história. Trad. Maria da Penha Villalobos e Lólio Lourenço de Oliveira, revista e atualizada pelo autor. São Paulo: EDUSP.

HOLLANDA, Heloísa Buarque de (2005) Rachel de Queiroz. Rio: Agir.

LEFEVERE, André (1992) “The system: patronage”. Translation, rewriting and the manipulation of literary frame, 1-11. London/New York: Routledge.

MICELI, Sérgio (2001) Intelectuais à brasileira. São Paulo: Companhia das Letras.

QUEIROZ, Rachel de \& QUEIROZ, Maria Luíza de (1999) Tantos anos. 3ª ed. São Paulo: Siciliano.

SCHLEIERMACHER, Friedrich (1992) From "On the different methods of translating”. Trad. Waltraud Bartscht. Rainer Schulte \& John Biguenet (orgs.). Theories of translation: an anthology of essays from Dryden to Derrida, 36-54. Chicago/London: The University of Chicago Press.

STEVENSON, Robert Louis (2004) “Markheim”. Trad. Rachel de Queiroz. Rubem Braga (org.) Contos ingleses: os clássicos. Rio de Janeiro: Ediouro.

STEVENSON, Robert Louis. Markheim. www.eastoftheweb.com/short-stories/UBooks. Acesso em 15/07/2005.

VENUTI, Lawrence (2002) “A formação de identidades culturais”. Escândalos da tradução: por uma ética da diferença, 129-167. Trad. Laureano Pelegrin, Lucinéia Marcelino Villela, Marleide Dias Esqueda e Valéria Biondo. Bauru, EDUSC.

(1995) The translator's invisibility: a history of translation. London/New York: Routledge.

VILLAÇA, Antônio Carlos (2001) José Olympio: o descobridor de escritores. Rio de Janeiro: Thex. 
WYLER, Lia (2003) Línguas, poetas e bacharéis: uma crônica da tradução no Brasil. Rio: Rocco. 